\title{
Synthesis and Characterization of a Thiadiazole/Benzoimidazole-Based Copolymer for Solar Cell Applications
}

\author{
GUAN-YU CHEN, ${ }^{1}$ SHANG-CHE LAN, ${ }^{1}$ PO-YU LIN, ${ }^{1}$ CHIH-WEI CHU, ${ }^{2,3}$ KUNG-HWA WEI ${ }^{1}$ \\ ${ }^{1}$ Department of Material Science and Engineering, National Chiao Tung University, Hsinchu 300, Taiwan \\ ${ }^{2}$ Research Center for Applied Sciences, Academia Sinica, Taipei 115, Taiwan \\ ${ }^{3}$ Department of Photonics, National Chiao Tung University, Hsinchu 300, Taiwan
}

Received 26 May 2010; accepted 9 July 2010

DOI: $10.1002 /$ pola. 24235

Published online in Wiley Online Library (wileyonlinelibrary.com).

\begin{abstract}
In this study, we synthesized a new polymer, PCTDBI, containing alternating carbazole and thiadiazole-benzoimidazole (TDBI) units. This polymer (number-average molecular weight $=25,600 \mathrm{~g} \mathrm{~mol}^{-1}$ ), which features a planar imidazole structure into the polymeric main chain, possesses reasonably good thermal properties $\left(T_{\mathrm{g}}=105{ }^{\circ} \mathrm{C} ; T_{\mathrm{d}}=396{ }^{\circ} \mathrm{C}\right)$ and an optical band gap of $1.75 \mathrm{eV}$ that matches the maximum photon flux of sunlight. Electrochemical measurements revealed an appropriate energy band offset between the polymer's lowest unoccupied molecular orbital and that of PCBM,
\end{abstract}

thereby allowing efficient electron transfer between the two species. A solar cell device incorporating PCTDBI and PCBM at a blend ratio of $1: 2(\mathrm{w} / \mathrm{w})$ exhibited a power conversion efficiency of $1.20 \%$; the corresponding device incorporating PCTDBI and $\mathrm{PC}_{71} \mathrm{BM}(1: 2, \mathrm{w} / \mathrm{w})$ exhibited a PCE of $1.84 \%$. (C) 2010 Wiley Periodicals, Inc. J Polym Sci Part A: Polym Chem 48: 4456-4464, 2010

KEYWORDS: carbazole; conjugated polymer; copolymerization; heteroatom-containing polymers; imidazole; solar cell
INTRODUCTION Research into conjugated polymers possessing extended arrays of delocalized $\pi$-electrons has advanced dramatically because of their potential application in organic optoelectronic devices, especially for the development of organic solar cells based on bulk heterojunctions (BHJs) of conjugated polymers. ${ }^{1-5}$ Solution-processed BHJ solar cells are simple-to-prepare devices featuring an electron-donating conjugated polymer and an electron-accepting fullerene as the active layer. Significant progress has been achieved recently on improving the power conversion efficiency (PCE) of polymer BHJ solar cells. For example, BHJ polymer solar cells based on regioregular poly(3-hexylthiophene)/[6,6]phenyl- $\mathrm{C}_{61}$-butyric acid methyl ester (rr-P3HT/PC ${ }_{61} \mathrm{BM}$ ) composites can exhibit PCEs of up to $6 \%$. $^{6-10}$ To increase the PCEs of these devices further, it will be necessary to improve the amount of light absorbed by the active polymer. For example, the absorption band of rr-P3HT covers wavelengths only of less than $650 \mathrm{~nm}$, whereas the maximum photon flux of sunlight is located at $700 \mathrm{~nm}(1.77 \mathrm{eV}) .{ }^{11}$ Thus, it is critical that the band gap of the polymer be narrowed so that it can absorb more photons (relative to rr-P3HT) from sunlight and, thereby, increase the photocurrent and the PCE of the corresponding devices.

Several low-band gap conjugated polymers ${ }^{12-17}$ have been synthesized that feature a main chain donor/acceptor structure to increase the degree of intrachain electron transfer, thereby resulting in partial charge separation along the polymer backbone and a lower band gap. Moreover, increasing the degree of delocalization of the $\pi$-electrons by increasing the coplanarity of the polymeric structure can also lead to a lower band gap. ${ }^{18-21}$

Carbazole derivatives are electron-donating materials that exhibit good hole-transporting characteristics ${ }^{22-24}$; copolymers based on carbazole derivatives display good performance in solar cell applications. ${ }^{25-30}$ For example, poly $\left[N-9^{\prime}\right.$-heptadecanyl-2,7-carbazole-alt-5,5-(4', , ${ }^{\prime}$-di-2-thienyl-2', $1^{\prime}, 3^{\prime}$-benzothiadiazole)] (PCDTBT) possesses a band gap of $1.88 \mathrm{eV}$ and exhibits a high PCE of $6.1 \%{ }^{31}$ Conjugated polymers containing imidazole-moieties as acceptor units have also been applied in solar cells exhibiting good performance (PCE = $\sim 4.1 \%)^{31-34}$ The planar structure of the imidazole moiety linked covalently to the polymeric side chain extends the effective length of conjugation and lowers the band gap.

In this study, we prepared a new planar imidazole unit and incorporated it into the polymeric main chain to extend the effective conjugation length of the system and to increase intramolecular charge transfer. Scheme 1 displays our route toward the synthesis of the thiadiazole/benzoimidazole (TDBI) unit M1. We expected the presence of the TDBI moieties in the polymer backbone to lower the band gap and that this polymer would possess a suitable lowest unoccupied 


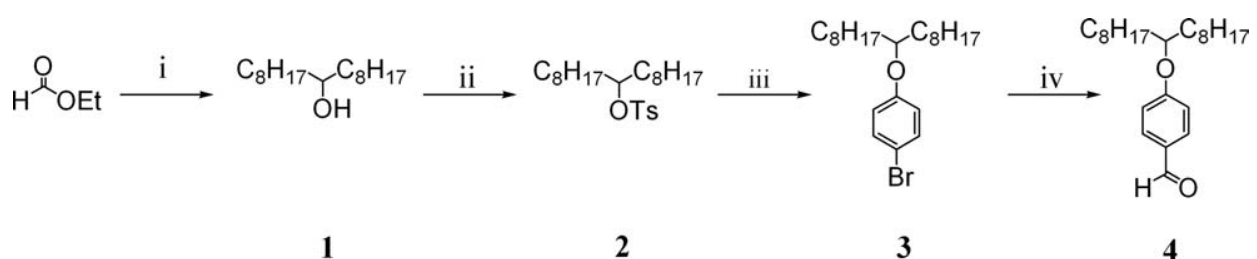

SCHEME 1 Reagents and conditions: (i) n-octylmagnesium bromide, $-78^{\circ} \mathrm{C}$; then $\mathrm{rt}$, overnight; (ii) $\mathrm{Et}_{3} \mathrm{~N}, \mathrm{Me}_{3} \mathrm{~N} \cdot \mathrm{HCl}, p-\mathrm{TsCl}, \mathrm{rt}, 2 \mathrm{~h}$; (iii) 4-bromophenol, $\mathrm{K}_{2} \mathrm{CO}_{3}, \mathrm{DMF}$, $110{ }^{\circ} \mathrm{C}$, overnight; (iv) $n$-BuLi, -78 ${ }^{\circ} \mathrm{C}, 1 \mathrm{~h}$; then dry DMF, rt, overnight; (v) $\mathrm{Br}_{2}, \mathrm{HBr}_{(\mathrm{aq})}, 100{ }^{\circ} \mathrm{C}, 3 \mathrm{~h}$; (vi) $\mathrm{TfOH}, \mathrm{HNO}_{3}, \mathrm{H}_{2} \mathrm{SO}_{4}$, rt, overnight; (vii) 2-tributylstannylthiophene, $\mathrm{PdCl}_{2}\left(\mathrm{PPh}_{3}\right)_{2}, \mathrm{THF}, 80{ }^{\circ} \mathrm{C}$, $20 \mathrm{~h}$; (viii) Fe powder, $\mathrm{AcOH}$, $80{ }^{\circ} \mathrm{C}, 5 \mathrm{~h}$; (ix) 4, $\mathrm{H}_{2} \mathrm{O}_{2}, \mathrm{HCl}, \mathrm{DMF}$, $\mathrm{rt}, 1 \mathrm{~h}$; (x) NBS, $0^{\circ} \mathrm{C}, 1 \mathrm{~h}$.

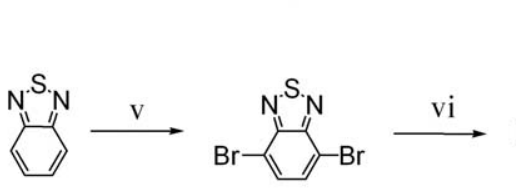

5

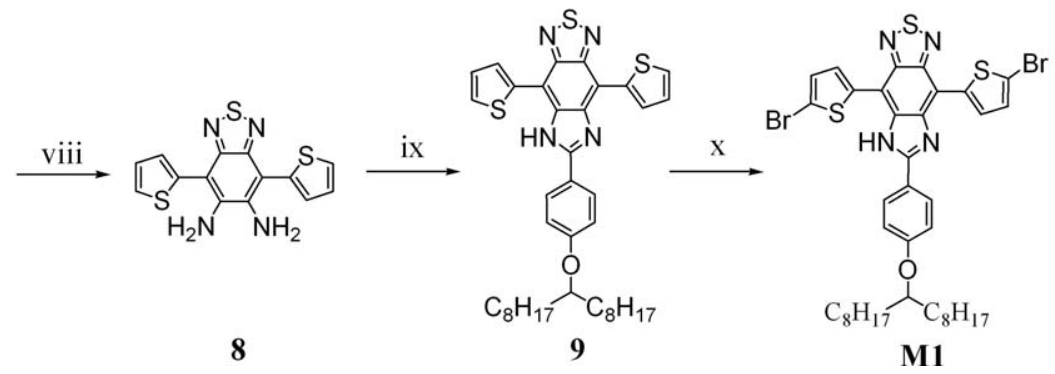

molecular orbital (LUMO) and sufficiently large LUMO offset for efficient electron transfer to PCBM. The LUMO energy level of the polymer must be positioned above that of PCBM by at least $0.3 \mathrm{eV}$ to overcome the exciton binding energy ${ }^{35,36}$; if the LUMO energy level of the polymer is very close to that of PCBM, there will be a loss of photocurrent. ${ }^{37}$ Since the electron-rich 2,7-carbazole possess good hole transport properties, incorporating 2,7-carbazole units into polymeric main chains provide not only a high degree of conjugation but also good intramolecular charge transfers. ${ }^{38,39}$ Scheme 2 displays the copolymerization of the TDBI (M1) and carbazole (M2) units, performed using a versatile Suzuki cross-coupling reaction.

\section{EXPERIMENTAL}

\section{Materials}

2,1,3-Benzothiadiazole ${ }^{40}$ and $\mathbf{M} 2^{27,41}$ were prepared according to reported procedures. Dimethylformamide (DMF) was dried over $\mathrm{MgSO}_{4}$; tetrahydrofuran (THF) and diethyl ether were dried over $\mathrm{Na}$ /benzophenone ketyl. All other reagents were used as received from commercial sources, without further purification.

\section{Measurements and Characterization}

${ }^{1} \mathrm{H}$ and ${ }^{13} \mathrm{C}$ NMR spectra were recorded using a Varian Unity-300 NMR spectrometer. Differential scanning calorimetry (DSC) was performed using a Perkin-Elmer Pyris DSC1 instrument operated at a heating rate of $10{ }^{\circ} \mathrm{C} \mathrm{min}{ }^{-1}$ under $\mathrm{N}_{2}$ purge. Thermogravimetric analysis (TGA) was performed using a Du Pont TGA 2950 instrument operated at a heating rate of $10{ }^{\circ} \mathrm{C} \mathrm{min}^{-1}$ under a $\mathrm{N}_{2}$ purge. The number-average $\left(M_{\mathrm{n}}\right)$ and weight-average $\left(M_{\mathrm{w}}\right)$ molecular weights were mea- sured through gel permeation chromatography (GPC) using a Waters chromatography unit interfaced with a Waters 2414 different refractometer. Three 5 - $\mu$ m Waters styragel columns were connected in series in decreasing order of pore size $\left(10^{4}, 10^{3}\right.$, and $\left.10^{2} \AA\right)$; polystyrene was the standard and THF was the eluant. UV-Vis absorption spectra were measured using an HP Agilent-8453 diode array spectrophotometer. Cyclic voltammetry (CV) was performed using a BAS 100 electrochemical analyzer operated at a scan rate of $100 \mathrm{mV}$ $\mathrm{s}^{-1}$; the solvent was anhydrous MeCN containing $0.1 \mathrm{M}$ tetrabutylammonium hexafluorophosphate $\left(\mathrm{TBAPF}_{6}\right)$ as the supporting electrolyte. A disk glassy carbon electrode coated with a thin film of polymer was used as the working electrode; a Pt wire was the counter electrode; $\mathrm{Ag} / \mathrm{Ag}^{+}(0.01 \mathrm{M}$ $\mathrm{AgNO}_{3}$ ) was the reference electrode; ferrocene/ferrocenium $\left(\mathrm{Fc} / \mathrm{Fc}^{+}\right)$was used as the internal standard. Topographic images of the copolymer/PCBM films were obtained using a Digital Instruments Nanoscope III atomic force microscope operated in the tapping mode under ambient conditions.

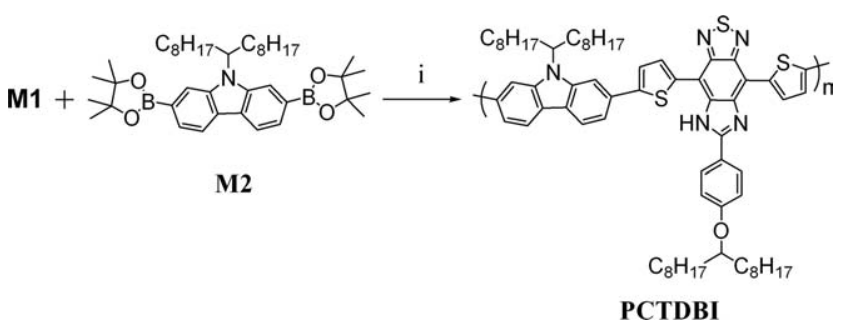

SCHEME 2 Reagents and conditions: (i) tetraethylammonium hydroxide, $\mathrm{Pd}_{2} \mathrm{dba}_{3}, \mathrm{THF}, 80^{\circ} \mathrm{C}, 8 \mathrm{~h}$. 
Solar Cells Device Fabrication and Characterization

An indium tin oxide (ITO, $10 \Omega$ ) coated glass substrate was cleaned sequentially with detergent, DI water, acetone, and isopropyl alcohol and then dried in the oven. Before use, the substrate was treated with oxygen plasma. The active layers were prepared by dissolving PCTDBI and PCBM at different weight ratios but with a fixed total concentration (1.5 wt \%) in 1,2-dichlorobenzene, and then the solutions were spincoating at a speed of $1500 \mathrm{rpm}$ onto the ITO/poly(3,4-ethylenedioxthiophene):poly(styrene sulfonate) (PETDOT:PSS) (30 $\mathrm{nm}$ ) substrates for $60 \mathrm{~s}$ (The model of spin coater is Laurell WS-400B-6NPP/LITE). The films were dried at room temperature. The thickness of each active layer was $\sim 90-100 \mathrm{~nm}$. Finally, Ca (40 nm) was thermally evaporated through a shadow mask and then $\mathrm{Al}(100 \mathrm{~nm})$ was evaporated to form the top electrode, and the device area of $0.12 \mathrm{~cm}^{2}$. All fabrications were performed in nitrogen-filled glovebox. The devices were measured under AM 1.5 radiation $\left(100 \mathrm{~mW} \mathrm{~cm}^{-2}\right)$ using an Agilent 4156 semiconductor parameter analyzer. The spectral mismatch factor was calculated by comparison of the solar simulator spectrum and the AM 1.5 spectrum at room temperature. The external quantum efficiency (EQE) was measured using a system established by Optosolar, Inc. Monochromatic light was created from 500-W Xe lamp source passing through a monochromator. The photocurrent of the device was detected using a lock-in amplifier under short-circuit conditions by illuminating the monochromatic incident beam. A calibrated mono silicon diode exhibiting a response at 300-800 $\mathrm{nm}$ was used as a reference.

\section{Synthetic Procedures \\ Heptadecan-9-ol (1)}

1-Bromooctane (22.3 mL, $152 \mathrm{mmol})$ in dry ether (30 mL) was added dropwise to a suspension of $\operatorname{Mg}(3.24 \mathrm{~g}, 135$ $\mathrm{mmol})$ in dry ether $(40 \mathrm{~mL})$ at room temperature. After stirring at room temperature for $1 \mathrm{~h}$, the resulting solution was added slowly to a solution of ethyl formate $(4.00 \mathrm{~g}, 54.0$ $\mathrm{mmol})$ in dry ether $(40 \mathrm{~mL})$ at $-78{ }^{\circ} \mathrm{C}$ and then warmed to room temperature. After stirring at room temperature overnight, the mixture was poured into water and extracted with $\mathrm{CH}_{2} \mathrm{Cl}_{2}(3 \times 100 \mathrm{~mL})$. The organic layer was dried $\left(\mathrm{MgSO}_{4}\right)$ and the solvent evaporated under reduced pressure. The crude product was purified through recrystallization (MeCN) to obtain 1 as a white solid (11.3 g, 82\%, mp: 58-62 ${ }^{\circ} \mathrm{C}$ ).

${ }^{1} \mathrm{H}$ NMR (300 MHz, $\mathrm{CDCl}_{3}, \mathrm{ppm}$ ): $\delta 3.59-3.58(\mathrm{~m}, 1 \mathrm{H}), 1.43-$ $1.38(\mathrm{~m}, 8 \mathrm{H}), 1.36-1.27(\mathrm{~m}, 21 \mathrm{H}), 0.88(\mathrm{t}, J=6.9 \mathrm{~Hz}, 6 \mathrm{H})$. ${ }^{13} \mathrm{C}$ NMR $\left(75 \mathrm{MHz} \mathrm{CDCl}_{3}, \mathrm{ppm}\right): \delta 72.3,37.7,32.1,30.0$, $29.9,29.5,25.9,22.9,14.3$. MS $(m / z):[\mathrm{M}]^{+}$calcd. for $\mathrm{C}_{17} \mathrm{H}_{36} \mathrm{O}$, 456.3; found 455 .

\section{9-Heptadecane p-Toluenesulfonate (2)}

A solution of $p$-TsCl $(4.09 \mathrm{~g}, 25.8 \mathrm{mmol})$ in $\mathrm{CH}_{2} \mathrm{Cl}_{2}(20 \mathrm{~mL})$ was added dropwise to a solution of $\mathbf{1}(6.00 \mathrm{~g}, 23.4 \mathrm{mmol})$, $\mathrm{Et}_{3} \mathrm{~N}$ (8.14 mL, $\left.58.51 \mathrm{mmol}\right)$, and $\mathrm{Me}_{3} \mathrm{~N} \cdot \mathrm{HCl}(2.23 \mathrm{~g}, 24.4$ mmol) in $\mathrm{CH}_{2} \mathrm{Cl}_{2}(30 \mathrm{~mL})$ in a $100-\mathrm{mL}$ flask at room temperature. After stirring for $2 \mathrm{~h}$, the mixture was poured into water and extracted with $\mathrm{CH}_{2} \mathrm{Cl}_{2}(3 \times 200 \mathrm{~mL})$. The organic phase was dried $\left(\mathrm{MgSO}_{4}\right)$ and the solvent evaporated under reduced pressure. The crude product was purified through column chromatography $\left(\mathrm{SiO}_{2}\right.$, EtOAc/hexane $\left.1: 9, R_{\mathrm{f}}: 0.76\right)$ to obtain 2 as a colorless oil (8.64 g, 90\%, mp: $50-54{ }^{\circ} \mathrm{C}$ ).

${ }^{1} \mathrm{H}$ NMR (300 MHz, $\left.\mathrm{CDCl}_{3}, \mathrm{ppm}\right): \delta 7.79(\mathrm{~d}, J=8.1 \mathrm{~Hz}, 2 \mathrm{H})$, $7.32(\mathrm{~d}, J=8.1 \mathrm{~Hz}, 2 \mathrm{H}), 4.56-4.52(\mathrm{~m}, 1 \mathrm{H}), 2.44(\mathrm{~s}, 3 \mathrm{H})$, 1.56-1.54 (m, 4H), 1.27-1.17 (m, 24H), $0.88(\mathrm{t}, J=6.9 \mathrm{~Hz}$, $6 \mathrm{H}) .{ }^{13} \mathrm{C} \mathrm{NMR}\left(75 \mathrm{MHz}, \mathrm{CDCl}_{3}, \mathrm{ppm}\right): \delta 144.9,135.1,129.8$, 128.0, 84.9, 34.4, 32.1, 29.6, 29.5, 29.4, 24.9, 22.9, 21.8, 14.3. MS (m/z): [M] ${ }^{+}$calcd. for $\mathrm{C}_{24} \mathrm{H}_{42} \mathrm{O}_{3} \mathrm{~S}, 410.3$; found 410 .

\section{1-Bromo-4-(heptadecan-9-yloxy)benzene (3)}

A mixture of 2 (2.00 g, $4.87 \mathrm{mmol}$ ), 4-bromophenol (1.01 g, $5.84 \mathrm{mmol}), \mathrm{K}_{2} \mathrm{CO}_{3}(3.36 \mathrm{~g}, 24.4 \mathrm{mmol})$, and DMF $(60 \mathrm{~mL})$ was stirred overnight at $110{ }^{\circ} \mathrm{C}$ in a three-necked flask. After cooling to room temperature, the reaction mixture was poured into water and extracted with EtOAc $(3 \times 100 \mathrm{~mL})$. The organic phase was then washed with water and brine. After evaporating the solvent, the crude product was purified through column chromatography $\left(\mathrm{SiO}_{2}\right.$, hexane, $R_{\mathrm{f}}$ : 0.84$)$ to obtain 3 as a colorless oil (1.79 g, 90\%).

${ }^{1} \mathrm{H}$ NMR (300 MHz, $\left.\mathrm{CDCl}_{3}, \mathrm{ppm}\right): \delta 7.34(\mathrm{~d}, J=8.7 \mathrm{~Hz}, 2 \mathrm{H})$, $7.75(\mathrm{~d}, J=8.7 \mathrm{~Hz}, 2 \mathrm{H}), 4.18-4.11(\mathrm{~m}, 1 \mathrm{H}), 1.64-1.61(\mathrm{~m}$, $4 \mathrm{H}), 1.40-1.25(\mathrm{~m}, 24 \mathrm{H}), 0.85(\mathrm{t}, J=7.2 \mathrm{~Hz}, 6 \mathrm{H}) .{ }^{13} \mathrm{C} \mathrm{NMR}$ (75 MHz, $\left.\mathrm{CDCl}_{3}, \mathrm{ppm}\right): \delta, 157.9,132.2,117.6,112.3,78.5$, $33.8,31.8,29.7,29.5,29.2,25.3,22.7,14.1$. MS $(\mathrm{m} / \mathrm{z}):[\mathrm{M}]^{+}$ calcd. for $\mathrm{C}_{23} \mathrm{H}_{39} \mathrm{BrO}, 410.22$; found 410 .

\section{4-(Heptadecan-9-yloxy)benzaldehyde (4)}

$n$-BuLi (2.5 M in hexane, $1.17 \mathrm{~mL}, 2.94 \mathrm{mmol}$ ) was added dropwise to a solution of 3 (1.00 g, $2.44 \mathrm{mmol})$ in dry THF $(10 \mathrm{~mL})$ in a $50-\mathrm{mL}$ three-necked flask at $-78{ }^{\circ} \mathrm{C}$. After stirring for $1 \mathrm{~h}$ at $-78{ }^{\circ} \mathrm{C}$, dry DMF $(0.280 \mathrm{~mL}, 3.62 \mathrm{mmol})$ was added to the reaction mixture, which was then stirred at room temperature for $8 \mathrm{~h}$. The reaction mixture was poured into water and extracted with EtOAc $(3 \times 100 \mathrm{~mL})$. The organic phase was dried $\left(\mathrm{MgSO}_{4}\right)$ and the solvent evaporated under reduced pressure. The crude product was purified through column chromatography $\left(\mathrm{SiO}_{2}\right.$, EtOAc/hexane 1:4, $R_{\mathrm{f}}: 0.87$ ) to obtain 4 as a viscous oil ( $\left.0.61 \mathrm{~g}, 70 \%\right)$.

${ }^{1} \mathrm{H}$ NMR (300 MHz, $\left.\mathrm{CDCl}_{3}, \mathrm{ppm}\right): \delta 9.84(\mathrm{~s}, 1 \mathrm{H}), 7.79(\mathrm{~d}, J=$ $8.7 \mathrm{~Hz}, 2 \mathrm{H}), 6.79(\mathrm{~d}, J=8.7 \mathrm{~Hz}, 2 \mathrm{H}), 4.34-4.31(\mathrm{~m}, 1 \mathrm{H})$, 1.66-1.60 (m, 4H), 1.40-1.23 (m, 24H), $0.85(\mathrm{t}, J=7.2 \mathrm{~Hz}$, $6 \mathrm{H}) .{ }^{13} \mathrm{C}$ NMR $\left(75 \mathrm{MHz}, \mathrm{CDCl}_{3}, \mathrm{ppm}\right): \delta$ 190.7, 164.0, 132.1, 129.4, 115.6, 78.4, 33.8, 31.8, 29.6, 29.5, 29.2, 25.3, 22.6, 14.1. MS (m/z): [M] ${ }^{+}$calcd. for $\mathrm{C}_{24} \mathrm{H}_{40} \mathrm{O}_{2}, 360.3$; found 361 .

\section{4,7-Dibromo-2,1,3-benzothiadiazole (5)}

$\mathrm{Br}_{2}$ (3.36 mL, $\left.65.5 \mathrm{mmol}\right)$ was added slowly to a mixture of 2,1,3-benzothiadiazole (3.00 g, $22.0 \mathrm{mmol}$ ) and $\operatorname{HBr}_{(\mathrm{aq})}(6.6$ $\mathrm{mL})$ at $100{ }^{\circ} \mathrm{C}$, followed by another charge of $\operatorname{HBr}_{(\mathrm{aq})}(5 \mathrm{~mL})$. After stirring at $100{ }^{\circ} \mathrm{C}$ for $3 \mathrm{~h}$, the reaction mixture was cooled to room temperature, poured into a saturated $\mathrm{Na}_{2} \mathrm{~S}_{2} \mathrm{O}_{3}$ solution, and then filtered. The crude product was purified through recrystallization (EtOH) to obtain $\mathbf{5}$ as a white solid (5.1 g, 80\%, mp: $184-188^{\circ} \mathrm{C}$ ). 
TABLE 1 Molecular Weights and Thermal Properties of PCTDBI

\begin{tabular}{llllll}
\hline & $M_{\mathrm{n}}$ & $M_{\mathrm{w}}$ & PDI & $T_{\mathrm{g}}\left({ }^{\circ} \mathrm{C}\right)$ & $T_{\mathrm{d}}\left({ }^{\circ} \mathrm{C}\right)^{\mathrm{a}}$ \\
PCTDBI & 25,600 & 32,560 & 1.27 & 105 & 396
\end{tabular}

a Temperature at which $5 \%$ loss of the initial weight occurred.

${ }^{1} \mathrm{H}$ NMR (300 MHz, $\left.\mathrm{CDCl}_{3}, \mathrm{ppm}\right): \delta 7.71$ (s, 2H). ${ }^{13} \mathrm{C} \mathrm{NMR}$ (75 $\left.\mathrm{MHz}, \mathrm{CDCl}_{3}, \mathrm{ppm}\right): \delta 153.3,132.7,114.2$. $\mathrm{MS}(\mathrm{m} / \mathrm{z})$ : $[\mathrm{M}]^{+}$calcd. for $\mathrm{C}_{6} \mathrm{H}_{2} \mathrm{Br}_{2} \mathrm{~N}_{2} \mathrm{~S}, 293.8$; found 293 .

\section{4,7-Dibromo-5,6-dinitro-2,1,3-benzothiadiazole (6)}

Trifluoromethanesulfonic acid (7.53 mL, $85.0 \mathrm{mmol})$ and $\mathrm{HNO}_{3}(1.8 \mathrm{~mL})$ were added dropwise to $\mathrm{H}_{2} \mathrm{SO}_{4}(10 \mathrm{~mL})$ at $0{ }^{\circ} \mathrm{C} .5$ (2.00 g, $\left.6.85 \mathrm{mmol}\right)$ was added to the acid mixture at $0{ }^{\circ} \mathrm{C}$; the system kept at room temperature overnight before being poured onto ice-water and then filtered. The filter cake was washed with water and dried. The crude product was purified through column chromatography $\left(\mathrm{SiO}_{2}, \mathrm{EtOAc} /\right.$ hexane $\left.1: 9, R_{\mathrm{f}}: 0.34\right)$ to obtain 6 as a white solid (1.28 g, 48\%, mp: $190-195^{\circ} \mathrm{C}$ ).

${ }^{13} \mathrm{C}$ NMR (75 MHz, $\left.\mathrm{CDCl}_{3}, \mathrm{ppm}\right): \delta 151.3,127.5,110.3$. MS $(\mathrm{m} / \mathrm{z}):[\mathrm{M}]^{+}$calcd. for $\mathrm{C}_{6} \mathrm{Br}_{2} \mathrm{~N}_{4} \mathrm{O}_{4} \mathrm{~S}, 383.8$; found 384 .

5,6-Dinitro-4,7-dithien-2-yl-2,1,3-benzothiadiazole (7)

$\mathrm{PdCl}_{2}\left(\mathrm{PPh}_{3}\right)_{2}(75 \mathrm{mg}, 0.11 \mathrm{mmol})$ was added to a solution of 2-tributylstannylthiophene (3.50 $\mathrm{mL}, 11.0 \mathrm{mmol})$ and 6 $(1.40 \mathrm{~g}, 3.67 \mathrm{mmol})$ in dry THF $(20 \mathrm{~mL})$ and then the reaction mixture was heated at $80{ }^{\circ} \mathrm{C}$ for $20 \mathrm{~h}$. After cooling to room temperature, the solvent was evaporated and the crude product washed with hexane and dried to yield $\mathbf{7}$ as an orange solid (1.2 g, 84.2\%, mp: $240-245{ }^{\circ} \mathrm{C}$ ).

${ }^{1} \mathrm{H}$ NMR (300 MHz, $\left.\mathrm{CDCl}_{3}, \mathrm{ppm}\right): \delta 7.75(\mathrm{dd}, J=1.2,5.1 \mathrm{~Hz}$, $2 \mathrm{H}), 7.52(\mathrm{dd}, J=1.2,3.6 \mathrm{~Hz}, 2 \mathrm{H}), 7.25-7.22(\mathrm{~m}, 2 \mathrm{H}) .{ }^{13} \mathrm{C}$ NMR (75 MHz, $\left.\mathrm{CDCl}_{3}, \mathrm{ppm}\right): \delta 152.2,141.8,131.4,131.0$, 129.5, 128.0, 121.5. MS (m/z): $[\mathrm{M}]^{+}$calcd. for $\mathrm{C}_{14} \mathrm{H}_{6} \mathrm{~N}_{4} \mathrm{O}_{4} \mathrm{~S}_{3}$, 390.0; found 390 .

5,6-Diamino-4,7-dithien-2-yl-2,1,3-benzothiadiazole (8) $\mathrm{AcOH}(50 \mathrm{~mL})$ was added to a mixture of $7(1.00 \mathrm{~g}, 2.56$ $\mathrm{mmol})$ and Fe powder $(1.70 \mathrm{~g}, 30.4 \mathrm{mmol})$. The mixture was heated at $80{ }^{\circ} \mathrm{C}$ for $5 \mathrm{~h}$ before being cooled to room temperature, poured into the water, and extracted with ether $(3 \times$ $100 \mathrm{~mL}$ ). The organic phase was washed sequentially with $5 \% \mathrm{NaOH}_{(\mathrm{aq})}$ and water and then dried $\left(\mathrm{MgSO}_{4}\right)$. Evaporation of the solvent under reduced pressure yielded $\mathbf{8}$ as an orange solid ( $0.77 \mathrm{~g}, 91 \%$, mp: $219-225^{\circ} \mathrm{C}$ ).

${ }^{1} \mathrm{H}$ NMR (300 MHz, $\left.\mathrm{CDCl}_{3}, \mathrm{ppm}\right): \delta 7.56(\mathrm{dd}, J=1.2,5.1 \mathrm{~Hz}$, $2 \mathrm{H}), 7.36(\mathrm{dd}, J=1.2,3.6 \mathrm{~Hz}, 2 \mathrm{H}), 7.25(\mathrm{t}, J=3.6 \mathrm{~Hz}, 2 \mathrm{H})$, 4.39 (s, 4H). ${ }^{13} \mathrm{C}$ NMR (75 MHz, $\left.\mathrm{CDCl}_{3}, \mathrm{ppm}\right): \delta 151.2,139.7$, 135.6, 128.8, 127.8, 127.5, 107.4. MS $(\mathrm{m} / \mathrm{z}):[\mathrm{M}]^{+}$calcd. for $\mathrm{C}_{14} \mathrm{H}_{10} \mathrm{~N}_{4} \mathrm{~S}_{3}, 330.0$; found 330 .

4,10-Bis(thiophene-2-yl)-7-[4-(heptadecan-9-yloxy)phenyl]-6H-[1,2,5]thiadiazole[3,4-g]benzoimidazole (9)

$\mathrm{H}_{2} \mathrm{O}_{2}(0.87 \mathrm{~mL})$ and $\mathrm{HCl}(0.34 \mathrm{~mL})$ were added to a solution of 8 (0.400 g, $1.21 \mathrm{mmol})$ and 4 (0.52 g, $1.45 \mathrm{mmol})$ in DMF
(15 mL). After stirring at room temperature for $1 \mathrm{~h}$, the reaction mixture was poured into water and extracted with EtOAc $(3 \times 100 \mathrm{~mL})$. The organic layer was dried $\left(\mathrm{MgSO}_{4}\right)$ and the solvent evaporated under reduced pressure. The crude product was purified through column chromatography $\left(\mathrm{SiO}_{2}\right.$, EtOAc/hexane 1:9, $\left.R_{\mathrm{f}}: 0.58\right)$ to yield 9 as a red solid (0.41 g, 50\%, mp: $140-145^{\circ} \mathrm{C}$ ).

${ }^{1} \mathrm{H}$ NMR (300 MHz, $\left.\mathrm{CDCl}_{3}, \mathrm{ppm}\right): \delta 9.63(\mathrm{~s}, 1 \mathrm{H}), 9.07$ (dd, $J$ $=1.2,3.9 \mathrm{~Hz}, 1 \mathrm{H}), 8.12(\mathrm{~d}, J=8.7 \mathrm{~Hz}, 2 \mathrm{H}), 8.01(\mathrm{dd}, J=1.2$, $3.9 \mathrm{~Hz}, 1 \mathrm{H}), 7.56(\mathrm{td}, J=0.9,5.7 \mathrm{~Hz}, 2 \mathrm{H}), 7.35-7.29(\mathrm{~m}, 2 \mathrm{H})$, $7.04(\mathrm{~d}, J=8.7 \mathrm{~Hz}, 2 \mathrm{H}), 4.37-4.33(\mathrm{~m}, 1 \mathrm{H}), 1.69-1.55(\mathrm{~m}$, $4 \mathrm{H}), 1.50-1.24(\mathrm{~m}, 24 \mathrm{H}), 0.86(\mathrm{t}, J=7.2 \mathrm{~Hz}, 6 \mathrm{H}) .{ }^{13} \mathrm{C} \mathrm{NMR}$ $\left(75 \mathrm{MHz}_{\mathrm{CDCl}}, \mathrm{ppm}\right): \delta$ 162.3, 156.8, 150.6, 150.1, 144.6, $137.1,136.8,136.6,130.9,128.9,128.3,128.1,127.3,125.9$, 120.2, 114.8, 113.8, 104.4, 98.8, 78.2, 33.8, 31.8, 29.7, 29.5, $29.3,25.4,22.6,24.1$. MS $(\mathrm{m} / \mathrm{z}):[\mathrm{M}]^{+}$calcd. for $\mathrm{C}_{38} \mathrm{H}_{46} \mathrm{~N}_{4} \mathrm{OS}_{3}$, 670.3; found 671 .
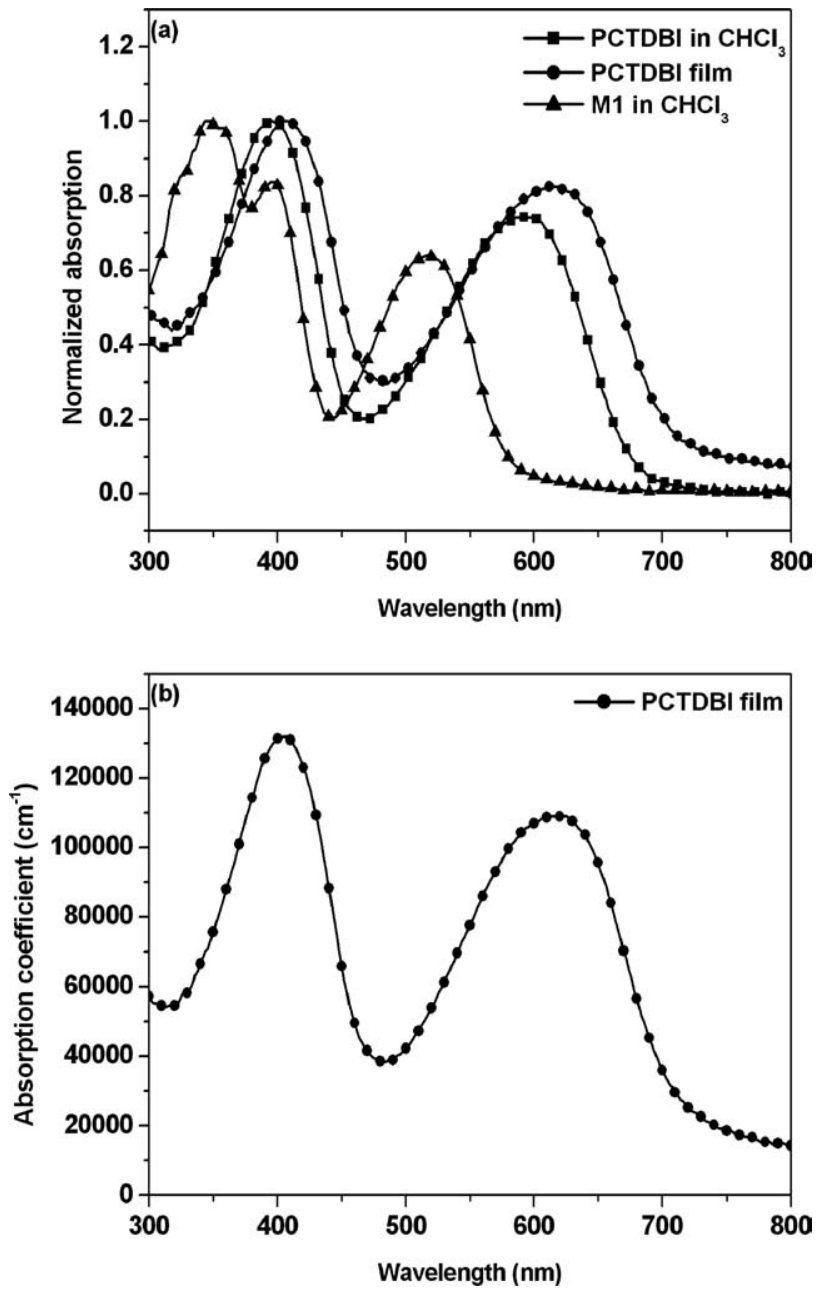

FIGURE 1 (a) Normalized UV-Vis absorption spectra of PCTDBI and M1. (The concentrations of solution were $1 \times 10^{-5} \mathrm{M}$; film (93 nm) was spin-coated on quartz glass). (b) Absoprtion coefficient of PCTDBI film (90 nm). The film was spin-coated on quartz glass). 
TABLE 2 Optical and Electrochemical Properties of PCTDBI

\begin{tabular}{|c|c|c|c|c|c|c|c|c|}
\hline & $\lambda_{\max }(\mathrm{nm})$ sol & $\lambda_{\max }(\mathrm{nm})$ film & $E_{\mathrm{g}}^{\mathrm{opt}}(\mathrm{eV})^{\mathrm{a}}$ & $E_{\text {onset }}^{\text {ox }}(\mathrm{V})$ & $E_{\text {onset }}^{\text {red }}(\mathrm{V})$ & HOMO (eV) & LUMO (eV) & $E_{\mathrm{g}}^{\mathrm{ec}}(\mathrm{eV})^{\mathrm{b}}$ \\
\hline PCTDBI & 394,596 & 408,620 & 1.75 & 0.33 & -1.83 & -5.13 & -2.97 & 2.16 \\
\hline
\end{tabular}

\section{4,10-Bis(5-bromothiophene-2-yl)-7-}

\section{[4-(heptadecan-9-yloxy)-phenyl]-6H-[1,2,5]}

thiadiazole[3,4-g]benzoimidazole (M1)

NBS (0.270 g, $1.49 \mathrm{mmol})$ was added in five portions to a solution of 9 ( $0.500 \mathrm{~g}, 0.910 \mathrm{mmol})$ in DMF $(15 \mathrm{~mL})$ at $0{ }^{\circ} \mathrm{C}$. After $1 \mathrm{~h}$, the mixture was poured into water and extracted with EtOAc $(3 \times 100 \mathrm{~mL})$. The organic phase was dried $\left(\mathrm{MgSO}_{4}\right)$ and the solvent evaporated under reduced pressure. The crude product was purified through column chromatography $\left(\mathrm{SiO}_{2}\right.$, EtOAc/hexane 1:9, $\left.R_{\mathrm{f}}: 0.74\right)$ to yield $\mathbf{M 1}$ as a red solid ( $0.35 \mathrm{~g}, 57 \%$, mp: $\left.95-100{ }^{\circ} \mathrm{C}\right)$.

${ }^{1} \mathrm{H}$ NMR (300 MHz, $\left.\mathrm{CDCl}_{3}, \mathrm{ppm}\right): \delta 9.27(\mathrm{~s}, 1 \mathrm{H}), 8.73(\mathrm{~d}, J=$ $4.2 \mathrm{~Hz}, 1 \mathrm{H}), 7.92(\mathrm{~d}, J=8.7 \mathrm{~Hz}, 2 \mathrm{H}), 7.61(\mathrm{~d}, J=3.9 \mathrm{~Hz}$, 1H), 7.26-7.25 (m, 1H), 7.19 (d, $J=3.9 \mathrm{~Hz}, 1 \mathrm{H}), 6.95$ (d, $J=$ $8.7 \mathrm{~Hz}, 2 \mathrm{H}), 4.38-4.34(\mathrm{~m}, 1 \mathrm{H}), 1.68-1.58$ (m, 4H), 1.46-1.25 (m, 24H), $0.86(\mathrm{t}, J=7.2 \mathrm{~Hz}, 6 \mathrm{H}) .{ }^{13} \mathrm{C}$ NMR $\left(75 \mathrm{MHz}^{\mathrm{CDCl}} \mathrm{CDC}_{3}\right.$, ppm): $\delta$ 162.6, 156.9, 151.6, 149.1, 138.5, 138.3, 133.2, 133.1, 131.6, 130.2, 129.0, 128.7, 119.8, 119.4, 117.2, 115.5, 114.9, 114.7 110.0, 78.3, 33.8, 31.9, 29.8, 29.5, 29.3, 25.3, 22.6, 14.1. Anal. Calcd. for $\mathrm{C}_{38} \mathrm{H}_{44} \mathrm{Br}_{2} \mathrm{~N}_{4} \mathrm{OS}_{3}$ : C, 55.07; H, 5.35; $\mathrm{N}, 6.76$. Found: C, 55.35; H, 5.62; N, 6.80\%. MS $(\mathrm{m} / \mathrm{z}):[\mathrm{M}]^{+}$ calcd. For $\mathrm{C}_{38} \mathrm{H}_{44} \mathrm{Br}_{2} \mathrm{~N}_{4} \mathrm{OS}_{3}$, 828.8; found 829 .

\section{PCTDBI}

A mixture of M1 (100 mg, $0.120 \mathrm{mmol}$ ), M2 (79.6 mg, 0.120 mmol), and tetraethylammonium hydroxide $(0.46 \mathrm{~mL})$ in THF $(1.60 \mathrm{~mL})$ was degassed at $50{ }^{\circ} \mathrm{C}$ for $10 \mathrm{~min}$. Tri(dibenzlideneacetone)dipalladium(0) $(2.20 \mathrm{mg}, 2.40 \mu \mathrm{mol})$ and triphenylphosphate $(2.50 \mathrm{mg}, 9.60 \mu \mathrm{mol})$ were added and then the reaction mixture was heated under reflux at $80{ }^{\circ} \mathrm{C}$ for

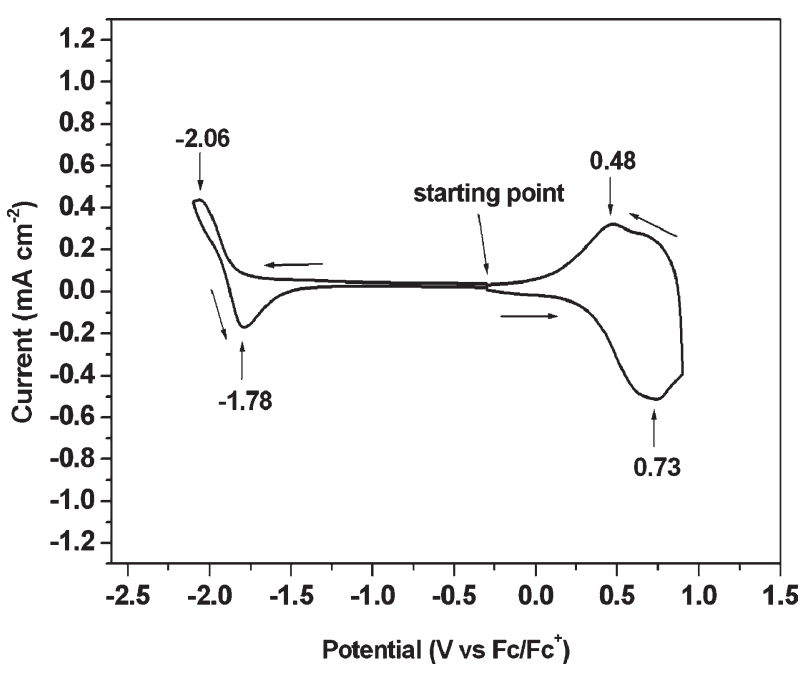

FIGURE 2 CV trace of PCTDBI.
8 h. Phenylboronic acid (40.8 $\mathrm{mg}, 0.250 \mathrm{mmol}$ ) was then added and the mixture stirred for $1 \mathrm{~h}$ at $80{ }^{\circ} \mathrm{C}$. Bromobenzene $(30.0 \mu \mathrm{L}, 0.250 \mathrm{mmol})$ was then added and the mixture stirred for another $1 \mathrm{~h}$ at $80{ }^{\circ} \mathrm{C}$. The resulting mixture was poured into $\mathrm{MeOH}(50 \mathrm{~mL})$ and filtered. The precipitated material was washed with acetone for $72 \mathrm{~h}$ in a Soxhlet apparatus and then dried (75 mg, 58\%).

${ }^{1} \mathrm{H}$ NMR (300 MHz, CDCl $\left.3, \mathrm{ppm}\right): \delta 9.04(\mathrm{br}, 2 \mathrm{H}), 7.97(\mathrm{br}$, 4H), 7.59 (br, 5H), 7.05 (br, 2H), 6.63 (br, 1H), 4.71 (br, 1H), 4.34 (br, 1H), 2.37 (br, 2H), 1.66 (br, 8H), 1.32-1.15 (m,
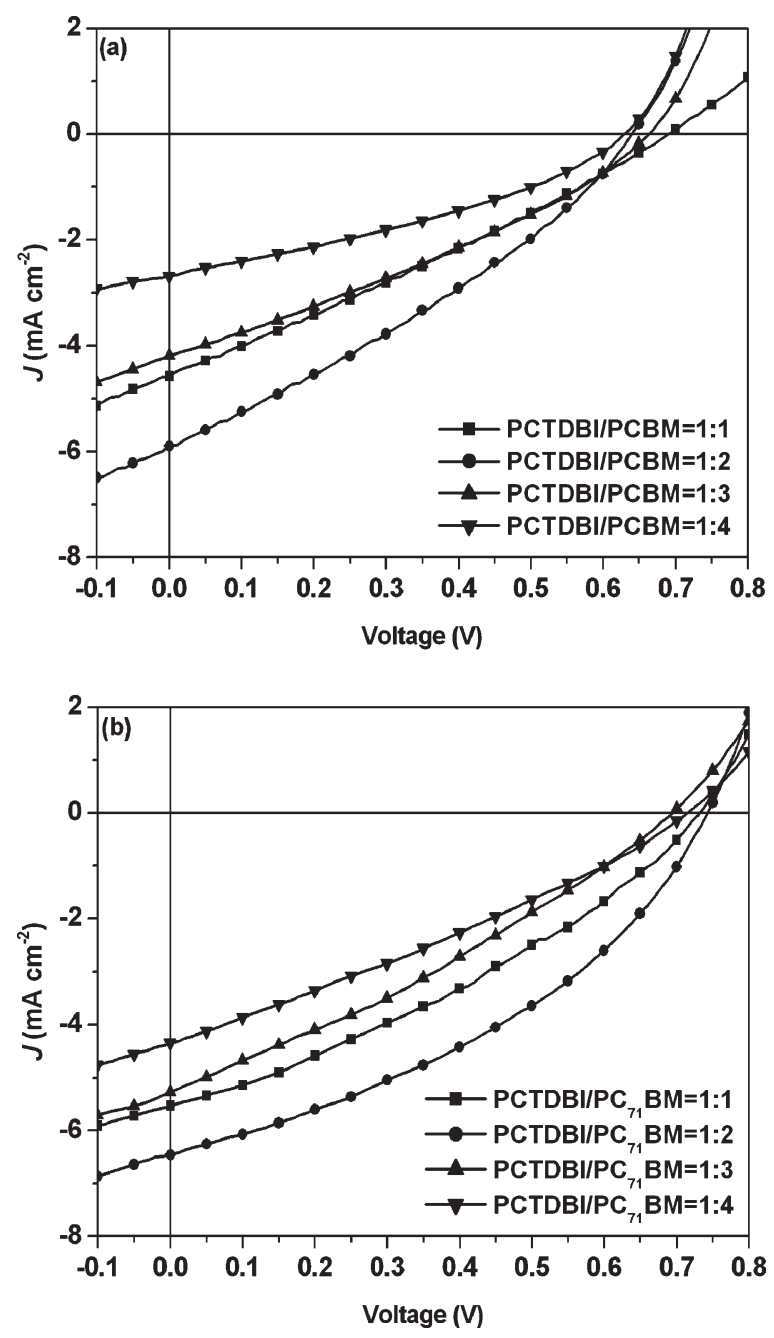

FIGURE 3 Current density-voltage characteristics of illuminated (AM 1.5G, $100 \mathrm{~mW} \mathrm{~cm}^{-2}$ ) polymer solar cells incorporating active layers of (a) PCTDBI/PCBM and (b) PCTDBI/PC ${ }_{71} \mathrm{BM}$. 
TABLE 3 Photovoltaic of Bulk Heterojunction Solar Cells ${ }^{a}$

\begin{tabular}{|c|c|c|c|c|}
\hline $\begin{array}{l}\text { Weight Ratio of } \\
\text { Active Layer }\end{array}$ & $\begin{array}{l}V_{\mathrm{oc}} \\
(\mathrm{V})\end{array}$ & $\begin{array}{l}J_{\mathrm{sc}} \\
\left(\mathrm{mA} \mathrm{cm}{ }^{-2}\right)\end{array}$ & FF & $\begin{array}{l}\text { PCE } \\
(\%)\end{array}$ \\
\hline PCTDBI/PCBM = 1:1 & 0.69 & 4.57 & 0.28 & 0.88 \\
\hline PCTDBI/PCBM = 1:2 & 0.64 & 5.89 & 0.32 & 1.20 \\
\hline PCTDBI/PCBM $=1: 3$ & 0.67 & 4.18 & 0.31 & 0.86 \\
\hline PCTDBI/PCBM $=1: 4$ & 0.64 & 2.69 & 0.34 & 0.58 \\
\hline PCTDBI/PC ${ }_{71} \mathrm{BM}=1: 1$ & 0.74 & 5.52 & 0.33 & 1. \\
\hline PCTDBI/PC ${ }_{71} \mathrm{BM}=1: 2$ & 0.75 & 6.46 & 0.38 & 1. \\
\hline PCTDBI/PC ${ }_{71} \mathrm{BM}=1: 3$ & 0.70 & 5.27 & 0.30 & 1.10 \\
\hline PCTDBI/PC ${ }_{71} \mathrm{BM}=1: 4$ & 0.72 & 4.37 & 0.29 & 0. \\
\hline
\end{tabular}

${ }^{a}$ Device structure: ITO/PEDOT:PSS/active layer/Ca/AI.

44H), 0.87-0.77 (m, 12H). Anal. Calcd. for $\mathrm{C}_{67} \mathrm{H}_{85} \mathrm{~N}_{5} \mathrm{OS}_{3}: \mathrm{C}$, 75.02; H, 7.99; N, 6.53. Found: C, 72.44; H, 7.87; N, 6.09\%.

\section{RESULTS AND DISCUSSION}

\section{Synthesis and Characterization}

Schemes 1 and 2 display the synthetic routes that we used to prepare the monomer M1 and the copolymer PCTDBI.
Heptadecan-9-ol (1), synthesized from n-octylmagnesium bromide and ethyl formate, was reacted with $p$-TsCl to yield 9-heptadecane $p$-toluenesulfonate (2), which we then treated with 4-bromophenol to obtain 1-bromo-4-(heptadecan-9yloxy)benzene (3). 4-(Heptadecan-9-yloxy)benzaldehyde (4) was synthesized through carbonylation of compound 3. 4,7Dibromo-5,6-dinitro-2,1,3-benzothiadiazole (6) was obtained through bromination and nitration of 2,1,3-benzothiadiazole; it was then treated with 2-tributylstannylthiophene to yield 5,6-dinitro-4,7-dithien-2-yl-2,1,3-benzothiadiazole (7) via Stille coupling; reduction of the nitro groups provided 5,6-diamino-4,7-dithien-2-yl-2,1,3-benzothiadiazole (8). We obtained 5,6-diamino-4,7-dithien-2-yl-2,1,3-benzothiadiazole (9) from the condensation of $\mathbf{4}$ and $\mathbf{8}$. Subsequently, we prepared M1 through the bromination of 9. We synthesized PCTDBI through Suzuki cross-coupling copolymerization of M1 and M2. The structures of the monomers and polymer were confirmed using ${ }^{1} \mathrm{H}$ and ${ }^{13} \mathrm{C}$ NMR spectroscopy and elemental analysis. Table 1 lists the molecular weights, thermal decomposition temperature, and glass transition temperature of the polymer. The number-average weight $\left(M_{\mathrm{n}}\right)$ and polydispersity index (PDI) of polymer were 25,600 $\mathrm{g} \mathrm{mol}^{-1}$ and 1.27, respectively. This polymer exhibited good solubility in 1,2-dichlorobenzene and good thermal stability, as evidenced (a)
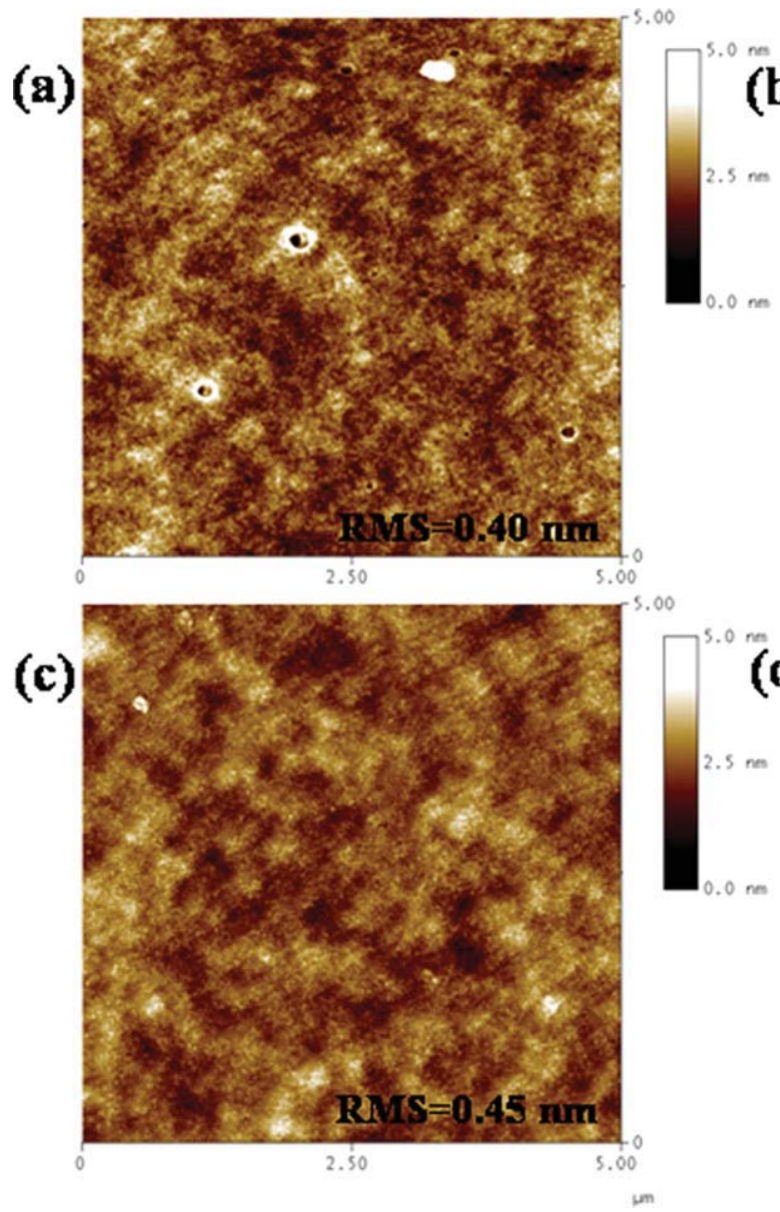
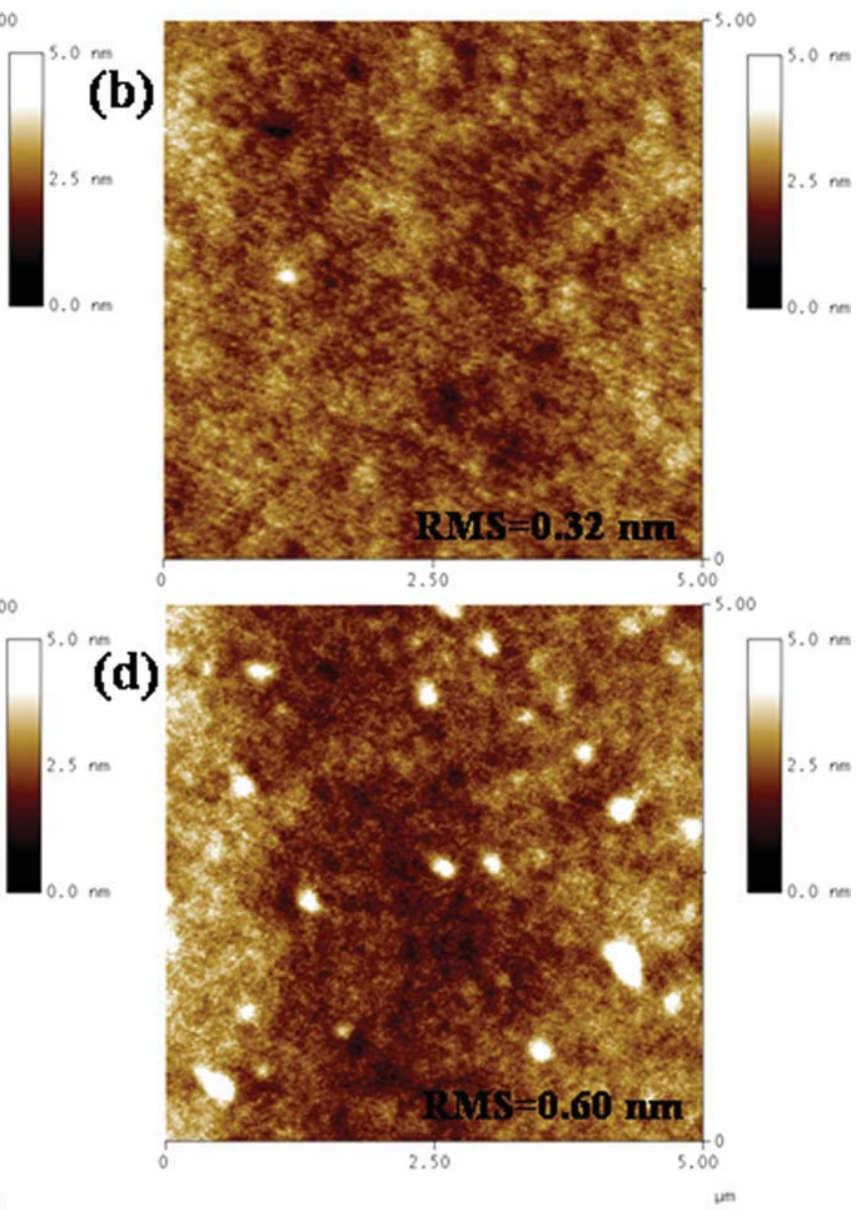

FIGURE 4 Topographic images of PCTDBI/PCBM films deposited at blend ratios of (a) 1:1, (b) 1:2, (c) 1:3, and (d) 1:4. 
by its $5 \%$ weight-loss temperature $\left(T_{\mathrm{d}}\right)$ of $396{ }^{\circ} \mathrm{C}$ and glass transition temperature $\left(T_{\mathrm{g}}\right)$ of $105^{\circ} \mathrm{C}$.

\section{Optical Properties}

Figure 1(a) presents the absorption spectra of the polymer in dilute $\mathrm{CHCl}_{3}$ solution $\left(1 \times 10^{-5} \mathrm{M}\right)$ and as a solid film (93 nm) on quartz glass; Table 2 summarizes the corresponding optical data. In solution, PCTDBI exhibits two main absorption bands at $320-480$ and $490-720 \mathrm{~nm}$, respectively. Relative to the absorption spectrum of TDBI unit (M1), the absorption peak of PCTDBI exhibited a red shift of $78 \mathrm{~nm}$ that was caused by an increase in the conjugation length and the presence of intramolecular charge transport between TDBI and carbazole units. The longer-wavelength absorption maximum of PCTDBI was located at $596 \mathrm{~nm}$; this signal appeared at a higher wavelength than that of the corresponding carbazole-derivative polymer featuring benzothiadiazole segments as the acceptor $(545 \mathrm{~nm}),{ }^{27}$ presumably because the presence of the coplanar imidazole structure in the polymer backbone increased the degree of coplanarity which provided a longer effective conjugation length and better intramolecular charge transfer. ${ }^{42,43}$ The absorption spectrum of the polymer thin film was red-shifted related to its solution spectrum, suggesting intermolecular interactions and aggregation in the solid state. Figure $1(\mathrm{~b})$ displays the absorption coefficient $\left(1.09 \times 10^{5}\right.$ at $\left.\lambda_{\max }=620 \mathrm{~nm}\right)$ of PCTDBI film $(90 \mathrm{~nm})$ on quartz glass. The optical band gap $(1.75 \mathrm{eV})$, calculated from the absorption edge $(705 \mathrm{~nm})$ of the solid state film, is very close to the photon flux maximum of the solar spectrum $(\sim 1.77 \mathrm{eV})$, suggesting that PCTDBI might be a useful material for solar cell applications.

\section{Electrochemical Properties}

Cyclic voltammetry is used widely to investigate the redox behavior of polymers and to estimate their highest occupied molecular orbital (HOMO) and LUMO energy levels. We recorded the CV traces of PCTDBI in MeCN containing $0.1 \mathrm{M}$ $\mathrm{TBAPF}_{6}$ at a potential scan rate of $100 \mathrm{mV} \mathrm{s}^{-1}$. Figure 2 displays the electrochemical behavior of PCTDBI; Table 2 summarizes the CV data. PCTDBI exhibited reversible oxidation and reduction processes, the oxidation and reduction onset was located at $0.33 \mathrm{~V}$ and $-1.83 \mathrm{~V}$ that were attributed to the oxidation and reduction capability of PCTDBI, respectively. The HOMO and LUMO energy levels of PCTDBI were -5.13 and $-2.97 \mathrm{eV}$, respectively, according to the energy level of the ferrocene reference $(4.8 \mathrm{eV}$ below vacuum level). ${ }^{44,45}$ The higher HOMO level of PCTDBI than that of other carbazole-containing polymers, is presumably caused by the presence of electron-donating alkoxy groups in PCTDBI's side chain, ${ }^{46,47}$ and the higher PCTDBI's HOMO in turn results in a lower $V_{\text {oc }}$ for its heterojunction device. The LUMO offset was $1.13 \mathrm{eV}$ relative to the LUMO energy level of PCBM $(-4.1 \mathrm{eV}),{ }^{48}$ suggesting that electrons could be transported efficiently to PCBM. The electrochemical band gap $\left(E_{\mathrm{g}}^{\mathrm{ec}}\right)$ was higher than the optical band gap $\left(E_{\mathrm{g}}^{\text {opt }}\right)$, presumably because of the interface energy barrier between the polymer film and the electrode surface. ${ }^{15,49}$
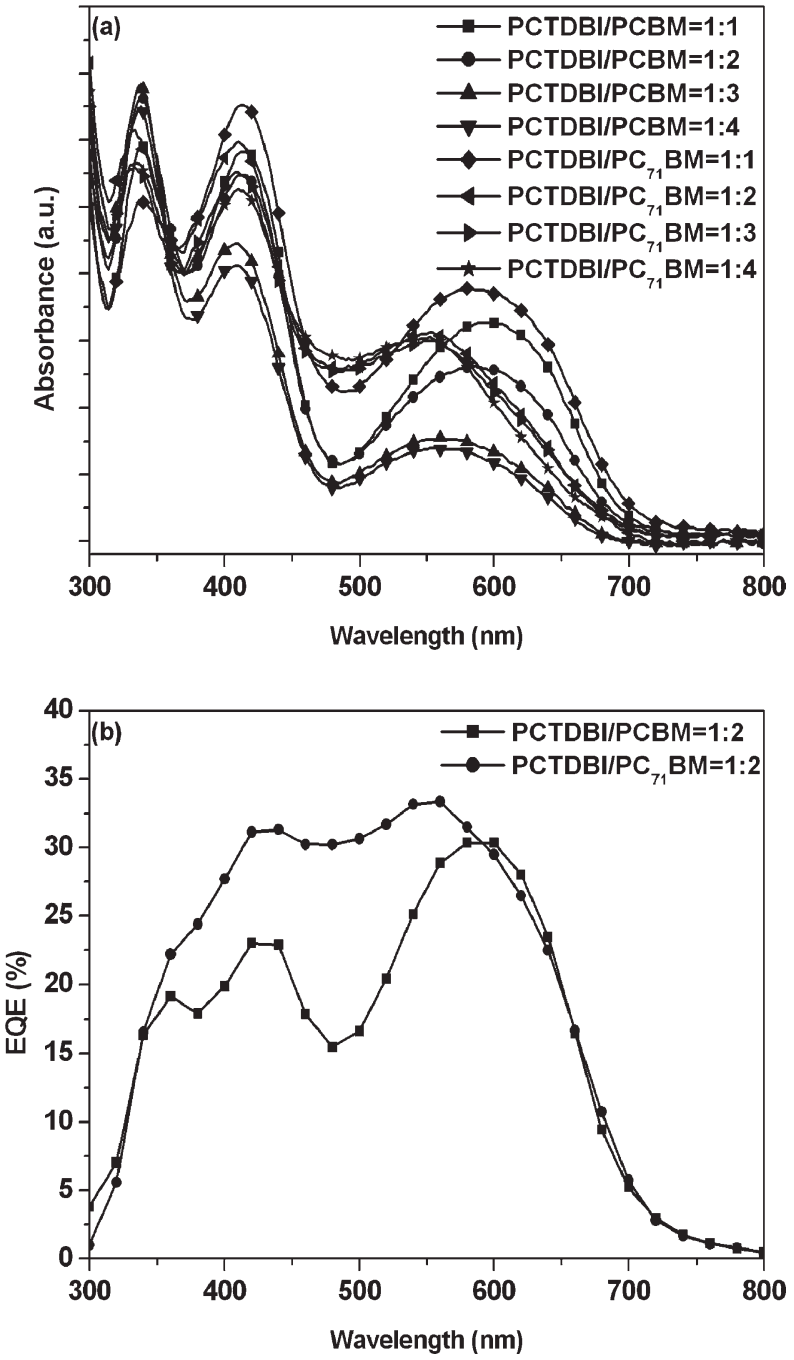

FIGURE 5 (a) Absorption spectra of active layer at various PCTDBI/PCBM and PCTDBI/PC 71 BM blend ratios. (b) Spectra of EQE spectra of active layers based on PCTDBI/PCBM and $\mathrm{PCTDBI} / \mathrm{PC}_{71} \mathrm{BM}$ (blend ratio, 1:2).

\section{Photovoltaic Properties}

Figure 3 displays the photovoltaic properties of devices having the structure ITO/PEDOT:PSS/PCTDBI:PCBM/Ca/Al under AM 1.5G illumination (100 $\left.\mathrm{mW} \mathrm{cm}{ }^{-2}\right)$. Table 3 summarizes the performance of the devices. These devices exhibited open circuit voltages $\left(V_{\text {oc }}\right)$ of $0.64-0.69 \mathrm{~V}$, which were related to the energy difference between the HOMO energy level of the copolymer and the LUMO energy level of PCBM. ${ }^{50,51}$ When we increased the amount of PCBM from a blend ratio of $1: 1$ to $1: 2$, the short circuit current density $\left.U_{\text {sc }}\right)$ increased significantly; it decreased upon increasing the loading weight ratio of PCBM to $1: 3$ and 1:4 because of the unfavorable morphologies of the active layer. Figure 4 displays AFM images of the surface morphologies of blended films of PCTDBI/PCBM, prepared from 1,2-dichlorobenzene solutions using a procedure identical to that used to fabricate the active layers of the devices. For PCTDBI/PCBM at 
weight ratios were 1:3 and 1:4, the images reveal rougher surfaces compared with that obtained at a blend ratio at 1:2. These rougher surfaces presumably arose from poor miscibility between PCTDBI and PCBM, which leaded to aggregation of PCBM that might limit the degree of charge dissociation and reduced the photocurrent. ${ }^{52-54}$ The AFM images suggested that devices based on high PCTDBI/PCBM weight ratios (1:3 or 1:4) would exhibit inefficient electron transport to the electrode and, thus, lower values of $J_{\mathrm{sc}}$. Accordingly, we obtained the highest value of $J_{\mathrm{sc}}\left(5.89 \mathrm{~mA} \mathrm{~cm}^{-2}\right)$ and PCE $(1.20 \%)$ at a blend ratio of $1: 2$. We also fabricated a solar cell device incorporating $\mathrm{PC}_{71} \mathrm{BM}$ in place of $\mathrm{PCBM}$ as the electron acceptor. Figure 5(a) reveals the absorption spectra of the active layer at various PCTDBI with PCBM or $\mathrm{PC}_{71} \mathrm{BM}$ weight ratios. As compare with the absorption spectra of PCTDBI/PCBM, the spectra of PCTDBI/PC ${ }_{71} \mathrm{BM}$ exhibit a broad absorption peaks around $500 \mathrm{~nm}$ that was contributed from $\mathrm{PC}_{71} \mathrm{BM}$. Figure 5 (b) displays the external quantum efficiency (EQE) curves of the two devices; we observe higher quantum efficiency at wavelengths below $550 \mathrm{~nm}$ for the PCTDBI/PC ${ }_{71} \mathrm{BM}$ device, which was presumably caused by the absorption of $\mathrm{PC}_{71} \mathrm{BM}$ in the shorter-wavelength range and thus increased photocurrent. ${ }^{3}$ The short circuit currents decreased when we increased the blend weight ratios of PCTDBI/PC $\mathrm{PC}_{71} \mathrm{BM}$ to $1: 3$ and $1: 4$, similar to the trend we observed for PCTDBI/PCBM. The device based on PCTDBI/PC ${ }_{71} \mathrm{BM}(1: 2)$ exhibited the highest values of $J_{\mathrm{sc}}$ $\left(6.46 \mathrm{~mA} \mathrm{~cm}^{-2}\right)$ and PCE (1.84\%).

\section{CONCLUSIONS}

The polymer PCTDBI, prepared through Suzuki coupling and containing alternating carbazole and TDBI units in its main chain, possesses good thermal properties $\left(T_{\mathrm{g}}=105{ }^{\circ} \mathrm{C} ; T_{\mathrm{d}}=\right.$ $396{ }^{\circ} \mathrm{C}$ ) and decent number-average molecular weight $\left(25,600 \mathrm{~g} \mathrm{~mol}^{-1}\right)$. The band gap of this polymer was $1.75 \mathrm{eV}$ as a result of incorporating planar thiadiazole/benzoimidazole units into the polymeric backbone. Moreover, this polymer exhibited a suitable LUMO energy level to allow efficient charge dissociation. A solar cell device fabricated with PCTDBI/PCBM at a blend ratio of $1: 2(\mathrm{w} / \mathrm{w})$ exhibited a value of $J_{\mathrm{sc}}$ of $5.89 \mathrm{~mA} \mathrm{~cm} \mathrm{~cm}^{-2}$ and a PCE of $1.20 \%$; these values increased to $6.46 \mathrm{~mA} \mathrm{~cm} \mathrm{~cm}^{-2}$ and $1.84 \%$, respectively, for the corresponding device incorporating PCTDBI/PC $\mathrm{P}_{71} \mathrm{BM}$ at a blend ratio of $1: 2(\mathrm{w} / \mathrm{w})$.

The authors thank the National Science Council, Taiwan, for financial support (NSC 98-2120M-009-006).

\section{REFERENCES AND NOTES}

1 Egbe, D. A. M.; Nguyen, L. H.; Schmidtke, K.; Wild, A.; Sieber, C.; Guenes, S.; Sariciftci, N. S. J Polym Sci Part A: Poly Chem 2007, 45, 1619-1631.

2 Zhang, S.; Guo, Y.; Fan, H.; Liu, Y.; Chen, H. Y.; Yang, G.; Zhan, X.; Liu, Y.; Li, Y.; Yang, Y. J Polym Sci Part A: Polym Chem 2009, 47, 5498-5508.
3 Wienk, M. M.; Kroon, J. M.; Verhees, W. J. H.; Knol, J.; Hummelen, J. C.; van Hal, P. A.; Janssen, R. A. J Angew Chem Int Ed 2003, 42, 3371-3375.

4 Zhang, F.; Svensson, M.; Andersson, M. R.; Maggini, M.; Bucella, S.; Menna, E.; Inganäs, O. Adv Mater 2001, 13, 1871-1874.

5 Hoppe, H.; Niggemann, M.; Winder, C.; Kraut, J.; Hiesgen, R.; Hinsch, A.; Meissner, D.; Sariciftci, N. S. Adv Funct Mater 2004, 14, 1005-1011.

6 Kim, J. Y.; Lee, K.; Coates, N. E.; Moses, D.; Nguyen, T. Q.; Dante, M.; Heeger, A. J. Science 2007, 317, 222-225.

7 Li, G.; Shrotriya, V.; Huang, J.; Yao, Y.; Moriarty, T.; Emery, K.; Yang, Y. Nat Mater 2005, 4, 864-868.

8 Chiu, M. Y.; Jeng, U. S.; Su, C. H.; Liang, K. S.; Wei, K. H. Adv Mater 2008, 20, 2573-2578.

9 Erb, T.; Zhokhavets, U.; Gobsch, G.; Raleva, S.; Stühn, B.; Schilinsky, P.; Waldauf, C.; Brabec, C. J. Adv Funct Mater 2005, 15, 1193-1196.

10 Kim, K.; Liu, J.; Namboothiry, M. A. G.; Carroll, D. L. Appl Phys Lett 2007, 90, 163511.

11 Coakley, K. M.; McGehee, M. D. Chem Mater 2004, 16, 4533-4542.

12 Beaujuge, P. M.; Subbiah, J.; Choudhury, K. R.; Ellinger, S.; McCarley, T. D.; So, F.; Reynolds, J. R. Chem Mater 2010, 22, 2093-2106.

13 Wienk, M. M.; Turbiez, M.; Gilot, J.; Janssen, R. A. J. Adv Mater 2008, 20, 2556-2560.

14 Huo, L.; Tan, Z. A.; Wang, X.; Zhou, Y.; Han, M.; Li, Y. J Polym Sci Part A: Polym Chem 2008, 46, 4038-4049.

15 Wang, E.; Wang, M.; Wang, L.; Duan, C.; Zhang, J.; Cai, W.; He, C.; Wu, H.; Cao, Y. Macromolecules 2009, 42, 4410-4415.

16 Helgesen, M.; Gevorgyan, S. A.; Krebs, F. C.; Janssen, R. A. J. Chem Mater 2009, 21, 4669-4675.

17 Mishra, S. P.; Palai, A. K.; Srivastava, R.; Kamalasanan, M. N.; Patri, M. J Polym Sci Part A: Polym Chem 2009, 47, 6514-6525.

18 Chen, G. Y.; Chiang, C. M.; Kekuda, D.; Lan, S. C.; Chu, C. W.; Wei, K. H. J Polym Sci Part A: Polym Chem 2010, 48, 1669-1675.

19 Becerril, H. A.; Miyaki, N.; Tang, M. L.; Mondal, R.; Sun, Y. S.; Mayer, A. C.; Parmer, J. E.; McGehee, M. D.; Bao, Z. J Mater Chem 2009, 19, 591-593.

20 Mondal, R.; Miyaki, N.; Becerril, H. A.; Norton, J. E.; Parmer, J.; Mayer, A. C.; Tang, M. L.; Brédas, J. L.; McGehee, M. D.; Bao, Z. Chem Mater 2009, 21, 3618-3628.

21 Li, K. C.; Hsu, Y. C.; Lin, J. T.; Yang, C. C.; Wei, K. H.; Lin, H. C. J Polym Sci Part A: Polym Chem 2009, 47, 2073-2092.

22 Xie, L. H.; Deng, X. Y.; Chen, L.; Chen, S. F.; Liu, R. R.; Hou, X. Y.; Wong, K. Y.; Ling, Q. D.; Huang, W. J Polym Sci Part A: Polym Chem 2009, 47, 5221-5229.

23 Morin, J. F.; Drolet, N.; Tao, Y.; Leclerc, M. Chem Mater 2004, 16, 4619-4626.

24 Kobayashi, N.; Koguchi, R.; Kijima, M. Macromolecules 2006, 39, 9102-9111. 
25 Zhou, E.; Cong, J.; Yamakawa, S.; Wei, Q.; Nakamura, M.; Tajima, K.; Yang, C.; Hashimoto, K. Macromolecules 2010, 43, 2873-2879.

26 Zou, Y.; Gendron, D.; Aïch, R. B.; Najari, A.; Tao, Y.; Leclerc, M. Macromolecules 2009, 42, 2891-2894.

27 Blouin, N.; Michaud, A.; Leclerc, M. Adv Mater 2007, 19 2295-2300.

28 Qin, R.; Li, W.; Li, C.; Du, C.; Veit, C.; Schleiermacher, H. F.; Andersson, M.; Bo, Z.; Liu, Z.; Inganäs, O.; Wuerfel, U.; Zhang, F. J Am Chem Soc 2009, 131, 14612-14613.

29 Blouin, N.; Michaud, A.; Gendron, D.; Wakim, S.; Blair, E.; Plesu, R. N.; Belletête, M.; Durocher, G.; Tao, Y.; Leclerc, M. J Am Chem Soc 2008, 130, 732-742.

30 Yuan, M. C.; Su, M. S.; Chiu, M. Y.; Wei, K. H. J Polym Sci Part A: Polym Chem 2010, 48, 1298-1309.

31 Park, S. H.; Roy, A.; Beaupré, S.; Cho, S.; Coates, N.; Moon, J. S.; Moses, D.; Leclerc, M.; Lee, K.; Heeger, A. J. Nat Photonics 2009, 3, 297-303.

32 Chang, Y. T.; Hsu, S. L.; Su, M. H.; Wei, K. H. Adv Funct Mater 2007, 17, 3326-3331.

33 Chang, Y. T.; Hsu, S. L.; Chen, G. Y.; Su, M. H.; Sing, T. A.; Diau, E. W. G.; Wei, K. H. Adv Funct Mater 2008, 18, 2356-2365.

34 Chang, Y. T.; Hsu, S. L.; Su, M. H.; Wei, K. H. Adv Mater 2009, 21, 2093-2097.

35 Koster, L. J. A.; Mihailetchi, V. D.; Blom, P. W. M. Appl Phys Lett 2006, 88, 093511.

36 Brabec, C. J.; Winder, C.; Sariciftci, N. S.; Hummelen, J. C.; Dhanabalan, A.; van Hal, P. A.; Janssen, R. A. J Adv Funct Mater 2002, 12, 709-712.

37 Zhang, F.; Bijleveld, J.; Perzon, E.; Tvingstedt, K.; Barrau, S.; Inganäs, O.; Andersson, M. R. J Mater Chem 2008, 18, 5468-5474.

38 Morin, J. F.; Leclerc, M.; Adès, D.; Siove, A. Macromol Rapid Commun 2005, 26, 761-778.
39 Leclerc, N.; Michaud, A.; Sirois, K.; Morin, J. F.; Leclerc, M. Adv Funct Mater 2006, 16, 1694-1704.

40 Neto, B. A. D.; Lopes, A. S. A.; Ebeling, G.; Goncalves, R. S.; Costa, V. E. U.; Quina, F. H.; Dupont, J. Tetrahedron 2005, 61, 10975-10982.

41 Freeman, A. W.; Urvoy, M.; Criswell, M. E. J Org Chem 2005, 70, 5014-5019.

42 Li, Y.; Li, H.; Xu, B.; Li, Z.; Chen, F.; Feng, D.; Zhang, J.; Tian, W. Polymer 2010, 51, 1786-1795.

43 Li, Y.; Li, Z.; Wang, C.; Li, H.; Lu, H.; Xu, B.; Tian, W. J Polm Sci Part A: Polm Chem 2010, 48, 2765-2776.

44 Zhou, E.; Yamakawa, S.; Tajima, K.; Yang, C.; Hashimoto, K. Chem Mater 2009, 21, 4055-4061.

45 Pommerehne, J.; Vestweber, H.; Guss, W.; Mahrt, R. F.; Bässler, H.; Porsch, M.; Daub, J. Adv Mater 1995, 7, 551-554.

46 Chen, H. Y.; Hou, J.; Zhang, S.; Liang, Y.; Yang, G.; Yang, Y.; Yu, L.; Wu, Y.; Li, G. Nat Photonics 2009, 3, 649-653.

47 Shi, C.; Yao, Y.; Yang, Y.; Pei, Q. J Am Chem Soc 2006, 128, 8980-8986.

48 Mühlbacher, D.; Scharber, M.; Morana, M.; Zhu, Z.; Waller, D.; Gaudiana, R.; Brabec, C. Adv Mater 2006, 18, 2884-2889.

49 Egbe, D. A. M.; Nguyen, L. H.; Hoppe, H.; Mühlbacher, D.; Saricific, N. S. Macromol Rapid Commun 2005, 26, 1389-1394.

50 Brabec, C. J.; Cravino, A.; Meissner, D.; Sariciftci, S.; Fromherz, T.; Rispens, M. T.; Sanchez, L.; Hummelem, J. C. Adv Funct Mater 2001, 11, 374-380.

51 Scharber, M. C.; Mühlbacher, D.; Koppe, M.; Denk, P.; Waldauf, C.; Heeger, A. J.; Brabec, C. J Adv Mater 2006, 18, 789-794.

52 Huang, J. H.; Ho, Z. Y.; Kekuda, D.; Chang, Y.; Chu, C. W.; Ho, K. C. Nanotechnology 2009, 20, 025202.

53 Hoppe, H.; Sariciftci, N. S. J Mater Chem 2006, 16, 45-61.

54 Nilsson, S.; Bernasik, A.; Budkowski, A.; Moons, E. Macromolecules 2007, 40, 8291-8301. 